1 Muldoon MF, Manuck SB, Matthews KA. Lowering cholesterol concentrations and mortality: a quantitative review of primary prevention trials. Br Med f 1990;301:309-14. (11 August.)

2 Horrobin DF. Lipid-lowering drugs and violence. $\mathrm{Br} f$ Psychiatry 1989;154:882-3.

\section{Cerebral mass lesions in patients with AIDS}

SIR, - We would like to comment on the case report presented by Dr $\mathbf{H}$ Montgomery ${ }^{1}$ and the subsequent letter from Mr I R Whittle concerning the safety of stereotactic biopsy guided by computed tomography. ${ }^{2}$

Brain biopsy guided by ultrasonography and carried out through a burr hole with the Berger neurobiopsy device is a simpler and cheaper alternative to the use of a stereotactic frame. ${ }^{3}$ It does not require the patient to be moved from the theatre to the scanning suite and back again under general anaesthesia. The Berger device is screwed into the burr hole in theatre and ultrasonography is performed to identify the lesion for biopsy. After alignment of the probe holder and needle guide the biopsy needle can be advanced to the appropriate depth. Assessment of the ultrasound image enables biopsy specimens to be taken from the echogenic rim of a lesion, where living cells are more likely to be found, rather than from the necrotic centre. Biopsy specimens can be taken from multiple sites through the one burr hole. Also, the lesion may be rescanned after each pass of the needle and any haemorrhage identified, enabling prompt treatment without necessitating return to a computed tomographic scanner.

We have just reported our initial experience with the device in 49 patients ${ }^{4}$ and consider it to be a valuable alternative to stereotaxis guided by computed tomography in many cases. In our small series there was no appreciable morbidity associated with the procedure and no deaths occurred.

WILLIAM HATELY RUDI L BORGSTEIN PETER J HAMLYN

The Royal London Hospital

London E1 IBB

1 Montgomery $\mathrm{H}$. Cerebral mass lesions in AIDS. $\mathrm{Br}$ Med $\mathcal{J}$ 1990;301:226-8. (28 July.)

2 Whitle IR Cerebral mass lesions in patients with AIDS BrMed f 1990;301:386. (18-25 August.)

3 Kane R, O'Leary D, Mathews E. Intraoperative ultrasonography in neurosurgery. In: Schmidec HH, Sweet WH, eds. Operative neurosurgical techniques. 2nd ed. Vol 1. London: Saunders, 1988.

4 Borgstein RL, Moxon RA, Hately W, Hamlyn PJ, Arias J, Chumas P. Preliminary experience with the Berger neurobiopsy device for ultrasound guided aspiration and biopsy of intracranial lesions. Clin Radiol (in press).

\section{Cryptosporidium infection in thalassaemia major}

SIR,-We would like to comment on the short report by Drs Julia A Gledhill and John Porter.'

The clinical features of cryptosporidial infection are commonly seen in immunocompetent adults and children, ${ }^{2}$ and because cryptosporidium is the third commonest cause of non-viral gastroenteritis it should be sought in all patients with such symptoms. A single case cannot substantiate the claim that cryptosporidium infection may be more severe in patients with iron overload.

P J STANLEY B A CROSSE D P MAHER

Seacroft Hospital

Leeds LS146UH

1 Gledhill JA, Porter J. Diarrhoea due to cryptosporidium infection in thalassaemia major. Br Med $\mathcal{f}$ 1990;301:212-3. (28 July.) in thalassaemia major. Br Med $1990 ; 301: 212-3$. (28 July.)
Wolfson JS, Richler JM, Waldron MA Crytosporidiosis in immunocompetent patients. $N$ Engl J Med 1985;312:1278-81.

\section{Warning leak in subarachnoid haemorrhage}

SIR,-General practitioners faced with a patient with a headache will worry after reading Dr John $R$ Østergaard's statement that "all too often the diagnostic importance of a warning headache is missed." We believe that such claims made by specialists on the basis of retrospective analyses are suspect because of the highly selected nature of patients who reach doctors by referral. Specialists enter at the end of a diagnostic process that includes hundreds of patients never referredheadache is one of the 10 commonest presenting symptoms in British general practice. ${ }^{2}$

To substantiate his claim Dr $\emptyset$ stergaard should have provided the positive predictive value of the symptom - that is, the percentage of patients with a headache who have a subarachnoid haemorrhage. This information is not provided. A Canadian study of 265 patients presenting to family doctors with a new complaint of headache found a final diagnosis of vascular abnormality in just one patient. This gives a positive predictive value of $0 \cdot 4 \%$, which is of little diagnostic importance.

Fortunately, a paper by Duffy suggests that some general practitioners are identifying patients with warning leaks in subarachnoid haemorrhage. ${ }^{4}$ He describes 13 patients with warning symptoms of subarachnoid haemorrhage, eight of whom had consulted their general practitioner at the time of the warning leak. Five of these eight patients had been referred to hospital. It would be useful for both hospital doctors and general practitioners to know how these referral decisions were made.

Information on the diagnostic importance of a warning headache and other associated symptoms in subarachnoid haemorrhage will come from a general practice based prospective study.

PAUL KINNERSLEY PENNY OWEN JONATHAN RICHARDS

University of Wales College of Medicine,

Cardiff CF3 7PN

$1 \emptyset$ stergaard JR. Warning leak in subarachnoid haemorrhage. Br Med F 1990;301:190-1. (28 July.)

2 Morrell DC. Symptom interpretation in general practice. IR Coll Gen Pract 1972;22:297.

3 Headache Study Group of the University of Western Ontario. Predictors of outcome in headache patients presenting to family physicians: a one year prospective study. Headache family physicin

4 Duffy GP. The warning leak in spontaneous subarachnoid haemorrhage. Med f Aust 1983; :514-6.

SIR, - If words are important then the $B M \mathcal{F}$ has done neurosurgery a disservice by allowing $\mathrm{Dr}$ John R Østergaard to use the term warning leak when referring to subarachnoid haemorrhage. ' A minor haemorrhage is not a warning, it is the event. A second haemorrhage may occur, but this does not mean that the first was a warning any more than that the second was teaching the patient a lesson.

If, as Dr $\emptyset$ stergaard implies, sudden headache can be caused by expansion of an intracranial aneurysm or bleeding into the vessel wall then his suggested investigations (computed tomography and lumbar puncture) are inadequate because they would be most unlikely to give positive results. If such tests give positive results for blood then the patient has had a subarachnoid haemorrhage. There is thus no need for puzzlement over why a warning leak followed by a subarachnoid haemorrhage carries a poor prognosis-two subarachnoid haemorrhages are worse than one.

Institute of Neurological Sciences,

PHILIP BARLOW

Institute of Neurological Scien

Glasgow G51 4TF

Østergaard JR. Warning leak in subarachnoid haemorrhage. BrMed I 1990;301:190-1. (28 July.)
AUTHOR'S REPLY,-Dr Kinnersley and colleagues are worried by my message. But general practitioners need to be alert when a patient without a history of severe headaches presents with a severe, unremitting unusual pain in the head or face, particularly when it is hemifacial, periorbital, or accompanied by vomiting, photophobia, and perhaps meningism. I did not mean to cause alarm, but I am content if my paper has alerted doctors to the warning symptoms of subarachnoid haemorrhage.

Perhaps Mr Barlow is right, but the term warning leak is not my invention. In 1958 Gillingham noted the diagnostic importance of a less than catastrophic onset of subarachnoid haemorrhage, ${ }^{1}$ and in 1967 he used the term warning leak to describe it. ${ }^{2}$ Another term used is sentinel headache, ${ }^{3}$ but I prefer the older, more descriptive turn of speech.

University Hospital of Århus,

JOHN R ØSTERGAARD

DK 8000 Århus $C$

Denmark

1 Gillingham FJ. The management of ruptured intracranial aneurysm. Ann $R$ Coll Surg Engl 1958;23:89-117.

Gillingham FJ. The management of ruptured intracranial aneurysm. Scott Med management of $1967 ; 12: 377-83$.

3 Day JW, Radkin NH. Thunderclap headache: symptom of unruptured cerebral aneurysm. Lancet 1986;ii: 1247-8.

\section{Treatment for lichen sclerosus}

SIR, - I have several criticisms of Dr A B Shrank's response to the question about lichen sclerosus.

The treatment of choice is a potent topical corticosteroid, but this should be applied only once a day. Three times a day as suggested will not improve the response, but it will increase the risk of side effects. The addition of an antiseptic is unnecessary and is not recommended because of the possibility of the patient developing a contact sensitivity to the drug used. Patients who fail to respond to a potent corticosteroid ointment are unlikely to respond to topical oestrogen or testosterone or injection with alcohol.

The only indication for a vulvectomy in lichen sclerosus is the development of a squamous cell carcinoma. Lichen sclerosus not only returns at the edges of the excision but will continue to affect any remaining genital epidermis. It will even develop on grafted skin from elsewhere on the body. Surgical intervention is occasionally required in some women who have a severely narrowed introitus as a result of the disease. The most successful procedure in these cases is reconstruction with part of the posterior wall of the vagina.

Finally, leucoplakia is not a diagnosis. It literally means "white plaque" and is therefore a descriptive term. Unfortunately it now tends to be used synonymously with the word dysplastic, and it is for this reason that the International Society for Study of Vulvar Diseases has recommended withdrawal of the term. Appropriate and effective treatment is available that will alleviate the symptoms of lichen sclerosus, prevent further tissue destruction, and possibly decrease the risk of malignant change. Inappropriate treatment not only fails in these goals but often leaves the patient with further physical and psychological damage.

SALLIE NEILL

Westminster Hospital,

London SW1 2AP

1 Shrank AB. Any questions. Br Med J 1990;301:228. (28 July.)

AUTHOR'S REPLY, - Those privileged to work at Westminster Hospital benefit from a vulvar disease clinic, set up because of the late Dr Hugh Wallace's interest in lichen sclerosus et atrophicus, so Dr Sallie Neill's experience must be respected.

Nevertheless, in science there is always room for disagreement, and I and many colleagues do not 